\title{
Avaliação Quantitativa dos Lisossomos no Epitélio Glandular da Cápsula do Endometrioma e no Epitêlio do Endométrio de Pacientes com e sem Endometriose
}

Autor: Eduardo Vieira von Adamek Orientador: Prof. Dr. Vilmon de Freitas Co-orientador: Prof. Dr. Manuel de Jesus Simões

Dissertação apresentada à Universidade Federal de São Paulo - Escola Paulista de Medicina - para obtenção do Título de Mestre em Ginecologia, no dia 19 de julho de 2001.

Introdução: A endometriose é conceituada como uma doença não neoplásica, onde tecido semelhante ao endométrio é encontrado fora da cavidade uterina, mimetizando sua estrutura histológica e função. Sendo assim, apresenta semelhanças com a mucosa do útero, tanto nos aspectos morfológico e imunológico como no estrutural, no que diz respeito à hormôniodependência. A lesão mais típica da endometriose é o endometrioma que é uma formação cística, ovariana, repleta de líquido espesso e achocolatado, rodeada por cápsula densa e fibrosa. Nesta cápsula apresenta epitélio com estruturas semelhantes ao endométrio. A endometriose é uma doença hormônio-dependente que atinge mulheres no menacme, sendo que o seu caráter endócrino já foi comprovado por vários autores. A estrogênio-dependência de um tecido, pode ser estudada de maneira direta, pela verificação dos receptores hormonais in situ ou indiretamente, como pela análise dos lisossomos. Os lisossomos são organelas presentes no citoplasma da maioria das células animais e representam o maior componente do sistema vacuolar citoplasmático, ao lado do complexo de Golgi e dos retículos endoplasmáticos. É considerado um marcador da atividade estrogênica, visto que Freitas (1987) desvelou haver hormônio-dependência desta organela nas tubas uterinas humanas, sendo o estrogênio estimulador e a progesterona inibidora de sua proliferação.

Objetivos: O lisossomo é um verdadeiro marcador da atividade estrogênica e como o endometrioma não responde bem à terapia medicamentosa, propusemo-nos a quantificar os lisossomos presentes no epitélio glandular da cápsula do endometrioma e no epitélio do endométrio de pacientes com e sem endometriose.

Pacientes e Métodos: Analisamos o número de lisossomos no epitélio glandular do endométrio e na cápsula do endometrioma de mulheres portadoras de algia pélvica ou infertilidade, por meio de identificação histoquímica da fosfatase ácida presente nesta organela. Selecionamos 11 pacientes pertencentes à mesma faixa etária que, após vídeo-laparoscopia, foram divididas em dois grupos: um sem endometriose (GI), e outro com a doença (GII), que foi dividido em dois subgrupos: IIa (endométrio) e IIb (endometrioma). Os grupos eram homogêneos em relação à idade, paridade e fase do ciclo menstrual.

Resultados: Verificamos que o número de lisossomos no epitélio glandular do endométrio tópico das pacientes com endometrioma foi significantemente maior do que o do grupo sem endometriose, supondo-se haver, portanto, diferença no seu metabolismo. Notamos também que o número de lisossomos presentes no endométrio tópico das pacientes com endometrioma foi significantemente maior do que no epitélio glandular da cápsula do endometrioma. Isto mostra haver menor atividade da ação estrogênica no endometrioma, o que poderia explicar a sua menor resposta às várias modalidades de hormonioterapia antiestrogênica atualmente utilizadas.

Palavras-chave: Endométrio. Endometrioma. Endometriose.

\section{Estudo do Programa de Prevenção do Câncer do Colo do Útero no Município de Jaú -SP}

Autor: Lenira Maria Queiroz Mauad

Orientador: Prof. Dr. Paulo Traiman

Dissertação de Mestrado apresentada à Faculdade de Medicina de Botucatu - UNESP (Programa de Pós-Graduação em Ginecologia e Obstetrícia, área de concentração em Ginecologia), em 16 de outubro de 2001.

Este estudo teve como objetivo avaliar os resultados de um programa de Prevenção do Câncer do Colo do Útero na cidade de Jaú, Estado de São Paulo. Foram avaliados os fatores epidemiológicos relacionados ao carcinoma invasivo do colo uterino (CICU) nesta população e, através de uma análise estatística utilizando o teste do Qui-quadrado, sua relação com os exames alterados. Foram analisados 16.876 citologias e 12.128 mulheres que foram submetidas ao exame a partir da primeira relação sexual. Das mulheres da nossa amostra 30\% tinham entre 30 e 39 anos; 64\% referiram a coitarca antes dos 19 anos; 30\% referiram o primeiro coito antes dos 19 anos; em torno de 7\% relataram mais de 4 parceiros sexuais; $21 \%$ são tabagistas; $85 \%$ delas já havia se submetido ao exame colpocitológico anteriormente; 18\% referiram uso atual de ACO. Fo- 
ram encontrados $0,05 \%$ de exames inadequados; $4,5 \%$ classe I; 93\% classe II; aproximadamente 2,5\% dos exames estavam alterados sendo $1 \%$ NIC I, 0,2\% NIC II, 0,9\% NIC III e 0,01\% (2 pacientes) classe V (sugestivos de CICU). Observamos um aumento de 150\% na cobertura populacional do município (de 20,19\% iniciais atingimos a marca de 50,07\% em 98). Utilizando para análise estatística o teste do Qui-quadrado, observamos relação positiva entre os exames alterados e os principais fatores de risco: coitarca, número de parceiros e tabagismo. Concluímos que o programa foi eficaz nos moldes em que foi proposto mas, para atingir a meta preconizada pela OMS, novos esforços deverão ser realizados principalmente com intensificação da busca ativa e da divulgação do programa.

Palavras-chave: Colo do útero: lesões pré-neoplásicas. Citologia.

Coelhas

Autor: Henri Chaplin Rivoire

Orientador: Prof. Dr. Djalma José Fagundes

Dissertação de Mestrado apresentada ao Programa de Pós-Graudação em Técnica Operatória e Cirurgia Experimental Universidade Federal de São Paulo - Escola Paulista de Medicina - em 15 de agosto de 2001.

Com o objetivo de estudar a perviedade da tuba uterina de coelhas submetidas a aplicação transvaginal de nbutil-2-cianoacrilato, foram utilizados 20 animais (Orictolagus cuniculus) da linhagem Nova Zelândia, distribuídos em dois grupos, I (controle) e II (experimento). O grupo controle foi submetido a técnica operatória para esterilização pelo método proposto por Pomeroy e o grupo experimento teve a aplicação de $0,25 \mathrm{~mL}$ do adesivo cirúrgico n-butil-2-cianoacrilato no lúmen tubário através da via transvaginal, por meio de videovaginoscopia para cateterização das tubas uterinas e controle fluoroscópico. Após quatro semanas e quatro acasalamentos e o diagnóstico clínico da presença de gestação, foram submetidos a 3 testes de perviedade: histerossalpingografia (in vivo), teste de perviedade com corante azul de metileno (in vitro) e teste de pressão de rompimento (in vitro). Foi realizada a morfometria computadorizada digitalizada para medir o diâmetro tubário, a mucosa e o miossalpinge. A análise estatística foi feita pelo teste de análise de variância para os pesos dos animais, teste " $t$ " para análise comparativa dos pesos entre os grupos, teste exato de Fischer para presença ou não de gestação, presença ou não de perviedade na histerossalpingografia, no teste do azul de metileno e no teste de pressão de rompimento, e a morfometria foi avaliada pelo teste " $t$ " para grupos emparelhados e para grupos independentes, fixando-se em 5\% o nivel para rejeição da hipótese de nulidade. Os resultados mostraram vazamento em somente 1 tuba uterina do grupo II, embora o adesivo estivesse presente no lúmen tubário, o que foi não significante estatisticamente. Apresentou significância estatística a morfometria que mostrou aumento nas medidas do diâmetro tubário, da mucosa e do miossalpinge, que consideramos ser pela presença do polímero formado pelo adesivo, não havendo danos celulares. Concluímos que a aplicação transvaginal de n-butil-2-cianoacrilato no lúmen tubário de coelhas é tão eficaz para esterilização quanto o método de Pomeroy, no tempo estudado.

Palavras-chave: Tuba uterina. Esterilização. Adesivo cirúrgico.

\section{Dopplerfluxometria de Ducto Venoso - Avaliação da Acidemia em Fetos Prematuros com Centralização de Fluxo Sangüíneo}

Autor: Renato Augusto Moreira de Sá

Orientadores: Prof. Dr. Hermógenes Chaves Netto e Prof. Dr. Mário Jorge Barreto Viegas de Castro

Dissertação de Doutorado apresentada ao Programa de Pós-Graduação em Medicina - Área de Concentração em Ginecologia e Obstetrícia da Faculdade de Medicina da Universidade Federal de Minas Gerais, em 24 de agosto de 2001.

Objetivo: Avaliar a dopplerfluxometria do ducto venoso como marcador não invasivo de gasometria anormal em fetos prematuros centralizados.
Pacientes e Métodos: Estudo observacional transversal. A população em estudo consiste de 48 gestantes entre $25^{\mathrm{a}}$ e $33^{\mathrm{a}}$ semana de gestação, que apresentavam cen- 
tralização de fluxo sangüíneo fetal pela dopplerfluxometria. O tempo decorrido entre o diagnóstico de centralização fetal e o nascimento (cesariana sob anestesia peridural) foi de até 05 horas. Os seguintes parâmetros foram estudados: relação S/A do ducto venoso, $\mathrm{pH}$ e Base Excess (BE) de amostra do sangue da veia umbilical colhida imediatamente após o nascimento. A relação $\mathrm{S} / \mathrm{A}$ do ducto venoso foi considerada anormal quando maior que 3,6. Os conceptos foram classificados quanto ao resultado da gasometria. Considerada gasometria anormal quando $\mathrm{pH}<7,26$ e $\mathrm{BE}<-6$ $\mathrm{mMol} / \mathrm{L}$. Os resultados da dopplerfluxometria do ducto venoso (normal e anormal) e da gasometria do cordão (normal e anormal) foram cotejados em tabela $2 \times 2$. O estudo estatístico utilizado foi o Teste de Fisher, con- siderado significativo quando "p" foi menor ou igual a 0,05 .

Resultados: Sensibilidade 71\%, especificidade 94\%, taxa de falso-negativo 08\%, taxa de falso-positivo 04\%, valor preditivo positivo $83 \%$, valor preditivo negativo $89 \%$, probabilidade pré-teste $31 \%$, probabilidade pós-teste anormal $84 \%$ e probabilidade pós-teste normal $10 \%$. Teste de significância da associação: $p=0,0000082$ (Fisher)

Conclusão: A análise da relação S/A do ducto venoso se mostra adequada para o diagnóstico de gasometria anormal em fetos prematuros, centralizados.

Palavras-chave: Dopplervelocimetria. Gasometria. Sofrimento fetal.

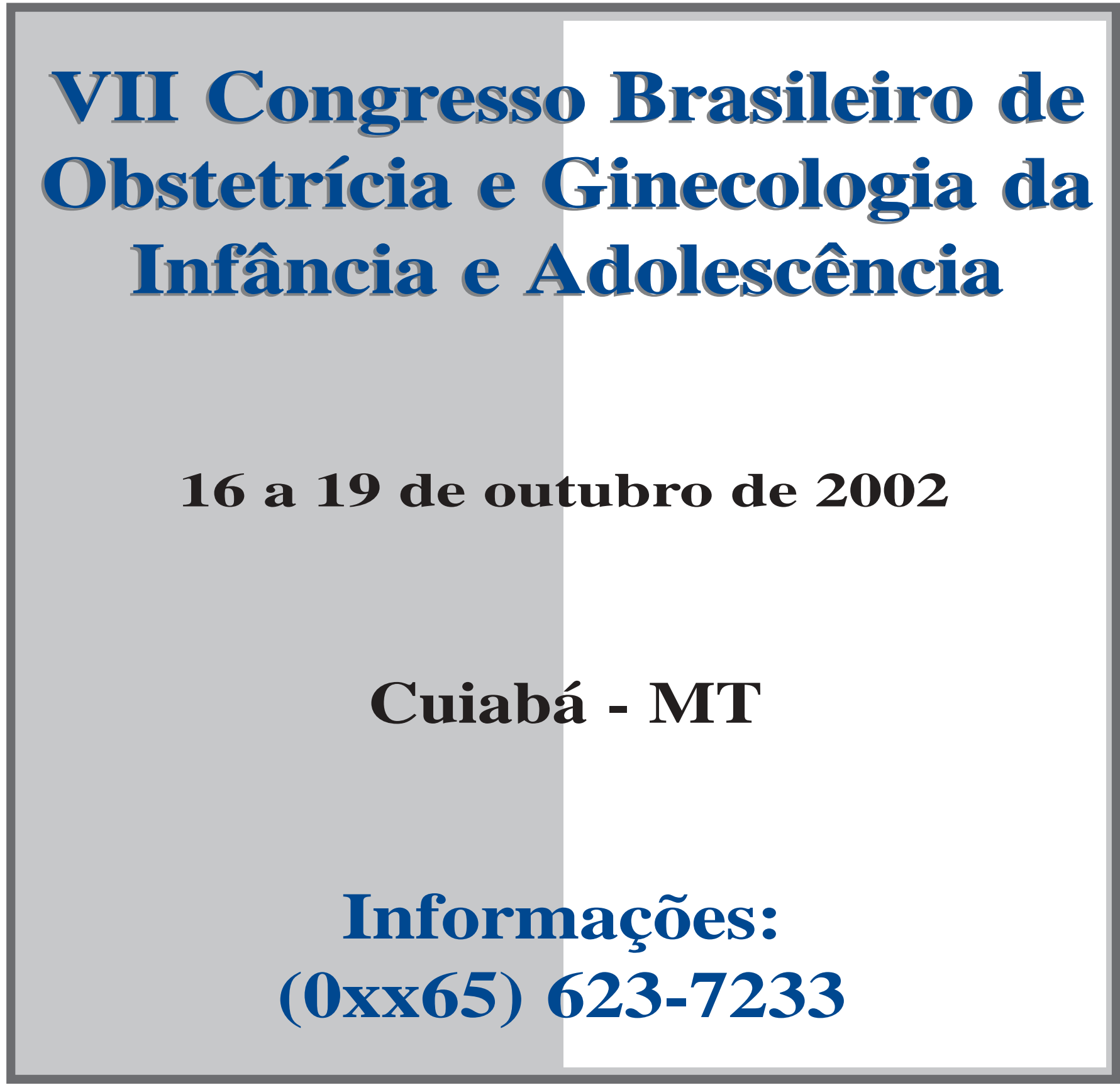

